\title{
Degradabilidade ruminal e digestibilidade intestinal da proteína de capim-elefante com três idades de corte
}

[Rumen degradability and intestinal digestibility of protein of elephant-grass at three cutting ages]

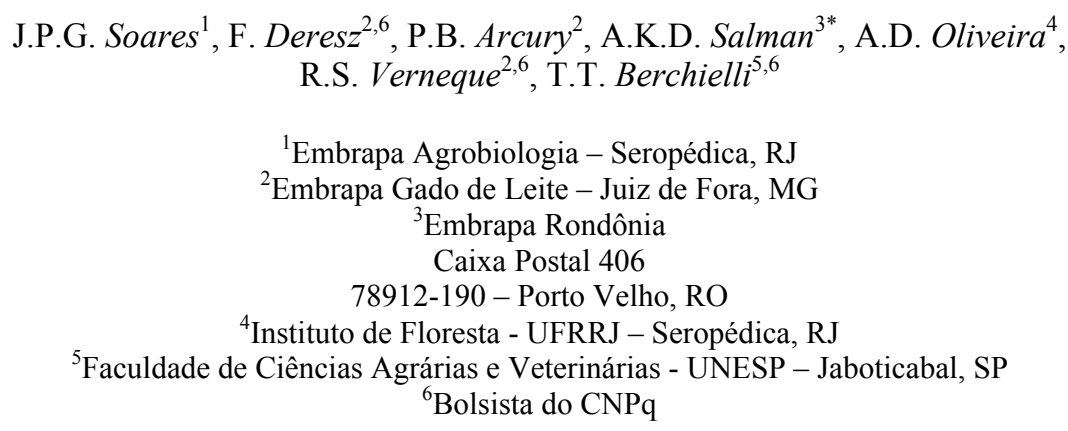

\section{RESUMO}

Determinaram-se a degradabilidade potencial (DP) e a digestibilidade intestinal da proteína não degradada no rúmen (DIPNDR) do capim-elefante em diferentes idades de rebrote (30, 45 e 60 dias) e comparou-se a técnica do saco de náilon móvel (in situ) com o método de três estádios (in vitro). Para tanto, utilizaram-se seis novilhos mestiços canulados no rúmen e duodeno alimentados exclusivamente com capim-elefante picado. $\mathrm{O}$ ensaio de degradabilidade foi realizado com amostras do capim incubadas no rúmen por 3, 6, 9, 12, 24, 48, 72, 96 e 120h. A digestibilidade intestinal foi determinada utilizando-se os resíduos de incubação por 24 horas. Na técnica in situ os resíduos em sacos de náilon foram colocados no duodeno e recuperados nas fezes. No método in vitro, os resíduos foram submetidos à digestão com $\mathrm{HCl}$-pepsina-pancreatina. Em amostras de capim com idades de 30, 45 e 60 dias foram observados valores de DP da proteína de 87,5; 87,8 e 83,8\%, respectivamente. A DIPNDR variou com a idade do capim e foi semelhante entre os métodos in situ e in vitro somente para o capim com 60 dias. O método in situ apresentou estimativa de digestibilidade intestinal mais coerente com as mudanças na composição química do capim-elefante decorrentes do envelhecimento.

Palavras-chave: bovino, Pennisetum purpureum, proteína de escape, sacos móveis

\begin{abstract}
The potential degradability (PD) and intestinal digestibility of ruminal escape protein (IDREP) of elephantgrass at 30, 45, and 60 days of regrowth were determined and the mobile bag technique (in situ) was compared to the three-stage method (in vitro). Thus, six cross-bred steers with rumen and duodenum canulas were used and fed exclusively with chopped elephant grass. The degradability trial was carried out with grass samples incubated in rumen by 3, 6, 9, 12, 24, 48, 72, 96, and $120 \mathrm{~h}$. The intestinal digestibility was determined using 24-h ruminal incubation residue. In the in situ technique, residues in nylon bags were placed in duodenum and recovered in feces. In the in vitro method, residues were digested with solution of HCl-pepsin-pancreatin. In samples of grass at 30, 45, and 60 days of age, the values of protein PD were 87.5, 87.8, and 83.8\%, respectively. The IDREP ranged with grass age and it was similar between in situ and in vitro methods only for 60-day old grass. Considering the changes in elephant-grass chemical composition due to aging, the in situ method supplied a more coherent estimative of intestinal digestibility.
\end{abstract}

Keywords: bovine, Pennisetum purpureum, escape protein, mobile bags

Recebido em 27 de maio de 2008

Aceito em 16 de março de 2009

*Autor para correspondência (corresponding author)

E-mail: aksalman@cpafro.embrapa.br

Apoio: FAPESP 


\section{INTRODUÇÃO}

Embora os sistemas de avaliação de proteínas dietéticas para ruminantes adotem valores constantes de digestibilidade intestinal da proteína não degradada no rúmen (PNDR), existe uma grande variação de valores entre os diferentes estádios de desenvolvimento da planta. Dessa forma, torna-se imprescindível estimar da maneira mais exata possível a digestibilidade intestinal da proteína do capim-elefante em diferentes idades de corte, já que essa gramínea é amplamente utilizada na alimentação de bovinos no Brasil. O seu uso pode ser realizado sob as formas de pastejo, feno, silagem ou por cortes regulares para fornecimento de forragem verde picada no cocho.

Várias metodologias têm sido desenvolvidas para estimar a digestibilidade intestinal, entre as quais se destacam a técnica do saco de náilon móvel (Hvelplund, 1985), a determinação do $\mathrm{N}$ insolúvel em detergente ácido (Goering et al., 1972), os métodos enzimáticos (Britton et al., 1986 citados por Calsamilgia e Stern, 1995) e o teste da disponibilidade da lisina (Faldet et al., 1991). A determinação da digestibilidade pósruminal da proteína não degradada no rúmen pela técnica de sacos de náilon móveis utilizando animais fistulados tem fornecido a maioria dos resultados observados na literatura, porém são laboriosos e caros. Para superar estes problemas, Casamiglia e Stern (1995) desenvolveram a técnica in vitro de três estádios para estimar a digestibilidade intestinal da proteína de vários alimentos por meio de um método de fácil aplicabilidade e que demanda menos tempo para obtenção dessas estimativas.

Dessa maneira, este trabalho teve como objetivos determinar a degradabilidade ruminal $\mathrm{e}$ a digestibilidade intestinal da proteína do capimelefante com 30, 45 e 60 dias de crescimento e comparar a técnica do saco de náilon móvel no rúmen com o método de três estádios in vitro.

\section{MATERIAL E MÉTODOS}

Para a realização do experimento, uma área de 4,5ha de latossolo vermelho-amarelo foi formada com capim-elefante (Pennisetum purpureum Schum. cv. Napier) utilizando-se $100 \mathrm{~kg} / \mathrm{ha}$ de $\mathrm{P}_{2} \mathrm{O}_{5}$ na forma de superfosfato simples e 3ton/ha de calcário dolomítico por ocasião do plantio.
Após cada corte de uniformização, foi feita adubação com $70 \mathrm{~kg} / \mathrm{ha}$ de nitrogênio e $70 \mathrm{~kg} / \mathrm{ha}$ de $\mathrm{K}_{2} \mathrm{O}$ utilizando-se o sulfato de amônio e o cloreto de potássio, respectivamente. A área foi dividida em faixas manejadas em sistema de corte para obtenção de forragem com 30, 45 e 60 dias, que eram oferecidas duas vezes ao dia para seis bovinos mestiços Holandês $x$ Zebu canulados no rúmen e duodeno com peso médio de $450 \mathrm{~kg}$, os quais foram confinados em baias individuais no período de julho a novembro de 2000.

$\mathrm{O}$ experimento foi dividido em três períodos de avaliações com duração de 30 dias cada, sendo 10 para a adaptação dos animais às dietas, 10 para a avaliação da degradabilidade $\mathrm{e}$ digestibilidade intestinal pela técnica do saco de náilon móvel e 10 dias para avaliação da digestibilidade intestinal in vitro $\mathrm{e}$ análises laboratoriais.

A degradabilidade in situ do capim foi determinada, utilizando-se, aproximadamente, $5 \mathrm{~g}$ de amostras do capim moídas (5mm), previamente secas a $55^{\circ} \mathrm{C}$ e acondicionadas em sacos de náilon $(7 \times 14 \mathrm{~cm})$ incubados no rúmen por $3,6,9,12,24,48,72,96$ e 120 horas. Antes da incubação, os sacos de náilon foram imersos em água em temperatura ambiente por 30 minutos. Para o cálculo da degradabilidade in situ da proteína bruta, foi utilizada a equação proposta por Mehrez e Ørskov (1977), com recomendações propostas por Nocek e Kohn (1988). A degradabilidade efetiva (DE) foi calculada considerando-se as taxas de passagem de 3\%/h adotadas segundo Soares (2002) e utilizando a equação proposta por Ørskov e McDonald (1979).

A digestibilidade intestinal foi estimada em amostras dos resíduos de capim-elefante após incubação ruminal por 24 horas, seguindo o método in situ descrito por Valadares Filho (1995), em que 0,7g de amostra dos resíduos moídos (1mm) foram colocados em sacos $(3 \times 5 \mathrm{~cm})$ de náilon com abertura da malha de 50$54 \mu \mathrm{m}$. Após a incubação por $1 \mathrm{~h}$ em solução de pepsina ácida a $38^{\circ} \mathrm{C}$, foram inseridos, dois a dois, em intervalos de $10 \mathrm{~min}$, via fístula duodenal, totalizando oito sacos por vaca. Após a coleta dos sacos nas fezes, os cálculos da 
digestibilidade foram feitos com base no desaparecimento da amostra contida nos sacos. $\mathrm{O}$ método de três estádios in vitro foi realizado de acordo com Calsamiglia e Stern (1995). Após determinar os teores de $\mathrm{N}$ nos resíduos de incubação ruminal, cerca de $15 \mathrm{mg}$ de $\mathrm{N}$ foram colocados em tubos $(50 \mathrm{~mL})$ para realização da digestão intestinal com $10 \mathrm{~mL}$ de HCL $0,1 \mathrm{~N}$ contendo $1 \mathrm{~g} / \mathrm{L}$ de pepsina $(\mathrm{pH}=1,9)$, durante 1 hora, a $38^{\circ} \mathrm{C}$. Em seguida, adicionaram-se $0,5 \mathrm{~mL}$ de $\mathrm{NaOH} 1 \mathrm{~N}$ e $13,5 \mathrm{~mL}$ de solução de pancreatina $\left(\mathrm{KH}_{2} \mathrm{PO}_{4} 0,5 \mathrm{M}\right.$ a $\mathrm{pH} 7,8$ contendo $50 \mathrm{ppm}$ de Thymol e $3 \mathrm{~g} / \mathrm{L}$ de pancreatina) para incubação por mais 24 horas. Ao finalizar a digestão, foram adicionados $3 \mathrm{~mL}$ de ácido tricloroacético (TCA-100\%) em cada tubo para encerrar a ação enzimática e precipitar as proteínas não digeridas. Cada tubo foi deixado 15 minutos e, posteriormente, centrifugado a $10.000 \times \mathrm{g}$ durante 15 minutos a $4^{\circ} \mathrm{C}$, sendo o sobrenadante analisado para $\mathrm{N}$ no aparelho LECO $^{1}$.

A porcentagem de proteína não degradada no rúmen com potencial para digestão no intestino (PNDR) foi considerada como sendo a quantidade de $\mathrm{N}$ do resíduo da incubação ruminal por 24 horas digerida em pepsina e pancreatina, multiplicada por 6,25 , dividida pela quantidade de proteína incubada e multiplicada por 100. Com base na diferença de peso nos resíduos dos sacos introduzidos no duodeno, calculou-se a digestibilidade intestinal da proteína não degradada no rúmen (DIPNDR).

A digestibilidade intestinal também foi calculada segundo o AFRC (Nutritive..., 1992) pela equação: DIPNDR= 0,9 (PNDR) - 6,25 NIDA, em que DIPNDR é a digestibilidade intestinal da proteína não degradada no rúmen; 0,9 é a constante para a digestibilidade intestinal da proteína bruta no intestino; PNDR é a proteína não degrada no rúmen com potencial para digestão intestinal; 6,25 é o fator de conversão de nitrogênio em proteína e NIDA é o nitrogênio insolúvel da fibra em detergente ácido.

Foram feitas determinação de matéria seca (MS), segundo o AOAC (Official..., 1990); leitura do nitrogênio (N) pelo aparelho LECO; determinações da fibra em detergente neutro

${ }^{1}$ Modelo TC400, Leco Corporation, St. Joseph, Michigan, EUA.
(FDN), fibra em detergente ácido (FDA), nitrogênio insolúvel em detergente neutro (NIDIN) e nitrogênio insolúvel em detergente ácido (NIDA), seguindo os procedimentos de Van Soest et al. (1991). Os teores de proteína insolúvel em FDN (PIDN) e FDA (PIDA) foram calculados multiplicando-se o valor de NIDN e NIDA pelo fator 6,25 .

As médias das digestibilidades intestinais da proteína não degradada no rúmen utilizando os dois métodos de estimativa foram comparadas pelo teste t a $5 \%$ de probabilidade, e as médias da composição química do capim em diferentes idades de corte foram comparadas pelo teste SNK a 5\% de probabilidade, utilizando os procedimentos do GLM do SAS/1990.

\section{RESULTADOS E DISCUSSÃO}

A composição química do capim-elefante com 30,45 e 60 dias de idade encontra-se na Tab. 1. Os teores de PB diminuíram, e os de FDN aumentaram com o avançar da idade do capim. Os valores de NIDA e PIDA do capim com 45 e 60 dias foram maiores que os do capim com 30 dias de corte. Os valores (\% da MS) de PB, FDN e FDA estão próximos aos observados por Silva et al. (2007), de 14,1; 9,2 e 7,8; de 60,6; 63,5 e 67,7 ; e de 39,$2 ; 40,7$ e 43,9 para capim-elefante com 33, 48 e 63 dias de rebrote, respectivamente. Clipes et al. (2005) e Paciullo et al. (2008) avaliaram nas diferentes estações do ano o capim-elefante sob pastejo com 30 e 42 dias de descanso, respectivamente, e observaram teores médios de PB de 14 e 12,6\% e de FDN de 70,6 e 57,9 .

Foram observadas variações nas diferentes idades de corte do capim-elefante em relação aos parâmetros de degradação da proteína bruta (Tab. 2). Entretanto, por se tratar de estimativas, não foram realizadas comparações estatísticas das variáveis entre tratamentos. Os dados referentes à degradabilidade efetiva e à taxa de degradação da fração b (c) da PB do capimelefante em diferentes idades foram mais elevados e mais baixos, respectivamente, que os encontrados por Lopes e Aroeira (1998) para o capim-elefante sob pastejo, $48,6 \%$ e $4,6 \% / \mathrm{h}$, e por Lopes et al. (1997) para capim-elefante cortado com 60 dias de crescimento, 38,6\% e $4,4 \% / \mathrm{h}$ 
Tabela 1. Teores de matéria seca (MS), proteína bruta (PB), fibra em detergente neutro (FDN), fibra em detergente ácido (FDA), nitrogênio insolúvel em detergente neutro (NIDN) e ácido (NIDA), proteína insolúvel em detergente neutro (PIDN) e ácido (PIDA) do capim-elefante cortado com 30, 45 e 60 dias de idade no período de janeiro a março de 2000

\begin{tabular}{ccccccccc}
\hline $\begin{array}{c}\text { Idade de } \\
\text { corte (dias) }\end{array}$ & MS & PB & FDN & FDA & NIDN & NIDA & PIDN & PIDA \\
\cline { 2 - 9 } & 12,8 & $11,4 \mathrm{a}$ & $62,9 \mathrm{~b}$ & 32,6 & 0,36 & $0,33 \mathrm{~b}$ & 2,3 & $2,1 \mathrm{~b}$ \\
45 & 15,9 & $10,5 \mathrm{ab}$ & $65,5 \mathrm{ab}$ & 33,2 & 0,90 & $0,80 \mathrm{a}$ & 5,6 & $5,0 \mathrm{a}$ \\
60 & 18,2 & $9,1 \mathrm{~b}$ & $70,1 \mathrm{a}$ & 35,8 & 1,11 & $0,86 \mathrm{a}$ & 6,9 & $5,4 \mathrm{a}$ \\
\hline EPM & 1,23 & 1,14 & 2,12 & 1,30 & 0,14 & 0,08 & 0,86 & 0,47 \\
\hline CV $(\%)$ & 19,4 & 9,0 & 2,5 & 17,5 & 18,5 & 5,7 & 18,5 & 5,7 \\
\hline
\end{tabular}

$\mathrm{EPM}=$ erro-padrão da média; $\mathrm{CV}=$ coeficiente de variação.

Valores seguidos por letras distintas na coluna diferem entre si pelo teste $\mathrm{SNK}(\mathrm{P}<0,05)$.

Tabela 2. Parâmetros de degradação da proteína bruta do capim-elefante cortado com 30, 45 e 60 dias de idade no período de janeiro a março de 2000

\begin{tabular}{cccccc}
\hline $\begin{array}{c}\text { Idade de corte } \\
\text { (dias) }\end{array}$ & $\mathrm{a}$ & $\mathrm{b}$ & $\mathrm{c} \mathrm{( \% /h)}$ & $\mathrm{DP}$ & $\mathrm{DE}$ \\
\cline { 2 - 5 } & 26,7 & 72,3 & 3,2 & 87,5 & 62,9 \\
45 & 18,0 & 76,1 & 3,2 & 87,8 & 58,7 \\
60 & 17,1 & 77,2 & 2,9 & 83,8 & 58,0
\end{tabular}

Parâmetros: $a=$ fração solúvel em água; $\mathrm{b}=$ fração insolúvel potencialmente degradável; $\mathrm{c}=$ taxa de degradação da fração $b ; \mathrm{DP}=$ degradabilidade potencial; $\mathrm{DE}=$ degradabilidade efetiva, considerando a taxa de passagem da MS de $3 \% / \mathrm{h}$ (Soares, 2002).

Essas diferenças entre os valores estimados neste estudo e os observados na literatura são atribuídas ao fato de a taxa de degradação e a da degradabilidade efetiva da PB de gramíneas estarem relacionadas a fatores como clima, época de colheita, tipo de solo e intensidade de adubação, além do manejo de utilização e da composição química da forragem (Soares, 2002). É possível, também, que outras características da forragem possam ter influenciado a utilização da PB no rúmen, como a taxa de redução das partículas, o tempo de colonização delas, assim como a taxa de saída da digesta ruminal (Ørskov et al., 1988).
As porcentagens de PDR, PNDR e DIPNDR do capim com idade de corte de 30, 45 e 60 dias são apresentadas na Tab. 3. O capim-elefante com 30 dias apresentou valores de PNDR próximos aos obtidos para volumosos por Londoño-Hernandez et al. (2002), que utilizaram o método de três estádios in vitro e observaram valores para a PDR e PNDR de $48,8 \%$ e $51 \%$; e de $49,1 \%$ e $50,3 \%$ para o capim-braquiária com 45 dias de crescimento e feno de capim-tifton, respectivamente.

Tabela 3. Estimativas do percentual de proteína degradada no rúmen (PDR), da proteína não degradada no rúmen (PNDR) e da digestibilidade intestinal da proteína não degradada no rúmen (DIPNDR) obtidas para o capim-elefante cortado nas idades de 30, 45 e 60 dias, utilizando-se o método do saco de náilon móvel (in situ)

\begin{tabular}{cccc}
\hline Idade de corte (dias) & PDR $(\%)$ & PNDR $(\%)$ & DIPNDR $(\%)$ \\
\hline 30 & 41,09 & 58,90 & 47,61 \\
45 & 59,54 & 40,45 & 38,36 \\
60 & 56,11 & 43,88 & 28,97 \\
\hline
\end{tabular}

As variações entre os valores de PDR e PNDR do capim com diferentes idades podem ter ocorrido devido às diferenças na composição química observada na Tab. 1, em que foi possível observar que os teores de NIDA e PIDA nos capins com 45 e 60 dias foram maiores em relação ao teor aos com 30 dias. Isto refletiu em diferenças nas frações insolúvel potencialmente degradável, na taxa de degradação, na degradabilidade efetiva (Tab. 2) e na 
digestibilidade intestinal da proteína não degradada no rúmen (Tab. 3) com o avançar da idade do capim. Segundo Euclides e Queiroz (2000), com a maturidade da planta, a matriz da parede celular torna-se mais complexa com a síntese de proteína associada aos componentes fibrosos, o que deixa a proteína menos acessível às bactérias do rúmen $\mathrm{e}$, consequentemente, menos degradável. De acordo com Mullahey et al. (1992), os teores de proteína degradável no rúmen aumentam com o desenvolvimento das gramíneas de clima tropical, principalmente quando se refere ao teor de PIDA.

$\mathrm{O}$ fato de o capim-elefante ter sido avaliado no período das águas também pode ter contribuído para o aumento da velocidade de acúmulo das frações indigestíveis na planta. Segundo McDonald et al. (1988), o maior crescimento de forragens durante o período chuvoso pode incrementar a quantidade de nitrogênio associado aos componentes da fibra, o que reduz sua disponibilidade para a ação das bactérias.

Erasmus et al. (1994), ao utilizarem a técnica dos sacos de náilon móveis, encontraram $32,7 \%$ de digestibilidade intestinal do feno de alfafa; e Branco et al. (2006) avaliaram, pela técnica de três estágios in vitro, a digestibilidade intestinal do feno de alfafa, do feno de aveia, do feno de tifton, do milheto e da silagem de rama de mandioca e verificaram que o menor valor foi de $39,9 \%$ para a silagem. Todos esses valores são mais altos que o de $28 \%$ proposto pelo NRC (Nutrient..., 1989) para digestibilidade intestinal da PNDR de volumosos. No presente estudo, apenas o capim com 60 dias apresentou digestibilidade intestinal da PNDR próxima ao valor preconizado pelo NRC.

Quando os métodos para estimar a digestibilidade intestinal da PNDR (Tab. 4) foram comparados, observou-se que somente para o capim com 60 dias de idade foram encontrados valores semelhantes entre os métodos in situ e o in vitro. Para os capins com 30 e 45 dias de idade, o método in vitro resultou em valores menores do que aqueles estimados pelo método in situ e pela equação preconizada pelo AFRC (Nutritive..., 1992).

Embora exista a possibilidade de erros de estimativa em função da contaminação microbiana nos sacos de náilon, os valores obtidos pelo método in situ foram os que mais se aproximaram daqueles preconizados pelo AFRC (Nutritive..., 1992) e estão mais coerentes com os resultados de NIDA e PIDA (Tab. 1). Acreditase que o aumento do nitrogênio e da proteína associada à fibra nos capins com 45 e 60 dias em relação ao capim com 30 dias tenha sido responsável pelos maiores valores de PDR e menores de PNDR observados (Tab. 3), o que também está relacionado aos menores valores de digestibilidade intestinal da PNDR dos capins com 45 e 60 dias.

Segundo Erasmus et al. (1994), a baixa digestibilidade intestinal da PNDR das forragens pode estar relacionada ao intenso processo de fermentação decorrente da ação dos microrganismos no rúmen. Nesse caso, a PNDR que passa para o intestino delgado pode ser, em grande parte, a proteína associada à parede celular (PIDA) que fica protegida da ação de enzimas e dos microrganismos do trato gastrintestinal inferior, o que acarreta diminuição da digestibilidade neste local. No caso dos alimentos concentrados, grande parte da PNDR é composta de proteína não associada à parede celular o que, consequentemente, resulta em maior digestibilidade (Van Straalen e Tamminga, 1990).

Tabela 4. Estimativas da digestibilidade intestinal da proteína não degradada no rúmen (DIPNDR) obtidas para o capim-elefante cortado nas idades de 30, 45 e 60 dias, utilizando os métodos do saco de náilon móvel no rúmen (in situ), o de três estádios (in vitro) e a equação do AFRC ${ }^{1}$

\begin{tabular}{cccc}
\hline $\begin{array}{c}\text { Idade de corte } \\
\text { (dias) }\end{array}$ & \multicolumn{3}{c}{ DIPNDR (\%) } \\
\cline { 2 - 4 } & In situ & In vitro & AFRC* \\
\hline 30 & $47,61 \mathrm{a}$ & $21,63 \mathrm{~b}$ & 49,69 \\
45 & $38,36 \mathrm{a}$ & $16,97 \mathrm{~b}$ & 31,90 \\
60 & $28,97 \mathrm{a}$ & $22,62 \mathrm{a}$ & 34,65 \\
\hline
\end{tabular}

${ }^{1}$ Nutritive... (1992). DIPNDR=0,9[(PNDR)-6,25 NIDA].

Médias seguidas por letras diferentes na mesma linha diferem entre si pelo teste $\mathrm{t}(\mathrm{P}<0,05)$. 
O método de três estádios in vitro apresentou valores mais próximos ao preconizado pelo NRC (Nutrient..., 1989) que considera a digestibilidade intestinal da proteína bruta de volumosos. No presente estudo, os resultados obtidos por este método não foram coerentes com a composição química dos capins com diferentes idades (Tab. 1). O capim com 30 dias de idade, embora com menores teores de NIDA e PIDA, apresentou proteína com digestibilidade intestinal próxima à do capim com 60 dias.

\section{CONCLUSÕES}

Com o avançar da idade de corte do capimelefante, ocorre aumento da proteína degradada no rúmen e diminuição do teor de proteína não degradada no rúmen devido ao aumento da proporção de nitrogênio e de proteína associados à fibra do capim. A digestibilidade intestinal da proteína não degradada no rúmen do capimelefante, estimada pela técnica dos sacos móveis, diminui com o aumento da idade de corte do capim. As técnicas dos sacos móveis e a de três estádios só fornecem estimativas semelhantes de digestibilidade intestinal da proteína não degradada no rúmen em amostras de capimelefante com idade de corte de 60 dias. A técnica dos sacos móveis em relação à dos três estádios in vitro fornece estimativas mais coerentes com a composição química do capim-elefante cortado em diferentes idades.

\section{REFERÊNCIAS BIBLIOGRÁFICAS}

BRANCO, A.F.; CONEGLIAN, S.M.; MAIA, F.J. et al. Digestibilidade intestinal verdadeira da proteína de alimentos para ruminantes Rev. Bras. Zootec., v.35, p.256-266, 2006.

BRITTON, R.A.; KLOPFENSTEIN, T.J.; CLEALE, R. et al. Methods of estimating heat damage in protein sources. In: DISTILLERS FEED CONFERENCE, 41., 1986, Cincinnati. Proceedings... Cincinnati: DFC, 1986. p.67

CALSAMIGLIA, S.; STERN, M.D. A three-step in vitro procedure for estimating intestinal digestion of protein in ruminants. J. Anim. Sci., v.73, p.1459-1465, 1995.

CLIPES, R.C.; COELHO DA SILVA, J.F.; DETMANN, E. Avaliação de métodos de amostragem em pastagens de capim-elefante (Pennisetum Purpureum, Schum) e capim- mombaça (Panicum maximum, Jacq) sob pastejo rotacionado. Arq. Bras. Med. Vet. Zootec., v.57, p.120-127, 2005.

ERASMUS, L.J.; BOTHA, P.M.; CRUYWAGEN, C.W. Amino acid profile and intestinal digestibility in dairy cows of rumenundegradable protein from various feedstuffs. $J$. Dairy Sci., v.77, p.541-551, 1994.

EUCLIDES, V.P.B.; QUEIROZ, H.P. Manejo de pastagens para produção de feno-em-pé. Campo Grande: Embrapa, CNPGC, 2000. Disponível em:

$<$ http://www.cnpgc.embrapa.br/eventos/2000/12 encontro/apostila.html/>. Acessado em: $26 \mathrm{dez}$. 2006.

FALDET, M.A.; VOSS, V.L.; BRODERICK, G.A. et al. Chemical, in vitro and in situ evaluation of heat-treated soybean proteins. $J$. Dairy Sci., v.74, p.2548-2554, 1991.

GOERING, F.K.; GORDON, C.H.; HEMKEN, R.W. Analytical estimatives of nitrogen digestibility in heat damaged forages. J. Dairy Sci., v.55, p.1275-1280, 1972.

HVELPLUND, T. Digestibility of rumen microbial protein and undegraded dietary protein estimated in the small intestine of sheep and by in saco procedure. Acta Agric. Scand., v.25, suppl., p.132-144, 1985.

LONDOÑO-HERNÁNDEZ, F.I.; VALADARES FILHO, S.C.; LANA, R.P. et al. Avaliação de dois métodos in vitro para determinar a cinética ruminal e a digestibilidade intestinal da proteína de vários alimentos. Rev. Bras. Zootec., v.31, p.256-266, 2002.

LOPES, F.C.F.; AROEIRA, L.J.M. Consumo, digestibilidade e degradabilidade e parâmetros ruminais em vacas Holandês x Zebu alimentadas com capim-elefante (Pennisetum purpureum Schum) picado. Arq. Bras. Med. Vet. Zootec., v.50, p.593-599, 1998

LOPES, F.C.F.; AROEIRA, L.J.M.; DAYRELL, M.S. Digestibilidade e degradabilidade do capim-elefante picado (Pennisetum purpureum Schum) em vacas Holandês x Zebu fistuladas no rúmen. In: REUNIÃO ANUAL DA SOCIEDADE BRASILEIRA DE ZOOTECNIA, 34., 1997, Juiz de Fora. Anais... Juiz de Fora: SBZ, 1997. p.498. (Resumo). 
McDONALD, P.; EDWARDS, R.A.; GREENHALGH, J.F.D. et al. Animal nutrition. New York: Longman Scientific Technical, 1988. $525 \mathrm{p}$.

MEHREZ, A.Z.; ØRSKOV, E.R. A study of the artificial fiber bag technique for determine the digestibility of feeds in the rumen. J. Agric. Sci., v.88, p.645-665, 1977.

MULLAHEY, J.J.; WALLER, S.S.; MOORE, K.J. et al. In situ ruminal protein degradation of switchgrass and smooth bromegrass. Agron. J., v.84, p.183-188, 1992.

NOCEK, J.E.; KOHN, R.A. In situ particle size reduction of alfafa and timothy hay as influence by form and particle size. J. Dairy Sci., v.71, p.932-945, 1988.

NUTRIENT requirements of dairy cattle. 6.ed. Washington, DC: National Academy Press, 1989. $157 \mathrm{p}$.

NUTRITIVE requirements of ruminant animals: Protein. Nutr. Abstr. Rev. Ser. B, v.62, p.787835, 1992.

OFFICIAL methods of analysis of the Association of Official Agricultural Chemists. 15.ed. Washington, DC: AOAC, 1990. 1298p.

ØRSKOV, E.R.; McDONALD, I. The estimation of protein degradability in the rumen from incubation measurements weighted according to rate of passage. J. Agric. Sci., v.92, p.499-503, 1979.

ØRSKOV, E.R.; REID, G.W.; KAY, M. Predicting of intake by cattle from degradation characteristics of roughage. Anim. Prod., v.46, p.29-34, 1988.
PACIULLO, D.S.C.; DEREZ, F.; LOPES, F.C.F. et al. Disponibilidade de matéria seca, composição química e consumo de forragem em pastagem de capim-elefante nas estações do ano. Arq. Bras. Med. Vet. Zootec., v.60, p.904-910, 2008.

SILVA, P.A.; VALADARES FILHO, S.C.; VALADARES, R.F.D. et al. Valor energético do capim-elefante em diferentes idades de rebrota e estimativa da digestibilidade in vivo da fibra em detergente neutro. Arq. Bras. Med. Vet. Zootec., v.59, p.711-718, 2007.

SOARES, J.P.G. Fatores limitantes do consumo de capim-elefante $c v$. Napier utilizando vacas leiteiras confinadas. 2002. 110f. Tese (Doutorado) - Faculdade de Ciências Agrária e Veterinária, Universidade Estadual Paulista, Jaboticabal.

VALADARES FILHO, S.C. Eficiência de síntese de proteína microbiana, degradação ruminal e digestibilidade intestinal da proteína bruta, em bovinos. In: SIMPÓSIO INTERNACIONAL SOBRE EXIGÊNCIAS NUTRICIONAIS DE RUMINANTES, 1995, Viçosa, MG. Anais... Viçosa, MG: SBZ, 1995. p.355-388.

VAN SOEST, P.J.; ROBERTSON, J.B.; LEWIS, B.A. Methods for dietary fiber, neutral detergent fiber, and nonstarch polysaccharides in relation to animal nutrition. J. Dairy Sci., v.74, p.35833597, 1991.

VAN STRAALEN, W.M.; TAMMINGA, S. Protein degradation of ruminant diets. In: WISEMAN, J.; COLE, D.J.A. (Eds). Feedstuffs evaluation. London: Butterworths, 1990. p.5572. 